\title{
Advantages and Disadvantages of Using Tangible Rewards by Teachers with Chinese Young Students
}

\author{
${ }^{1}$ The University of Warwick, Coventry, the United Kingdom \\ ${ }^{2}$ The University of British Columbia, Vancouver, Canada \\ ${ }^{*}$ Corresponding author. Email: ty0815@student.ubc.ca \\ These authors contributed equally.
}

Yuetyi Tsang ${ }^{1, \dagger}$, Tianyi Zhang ${ }^{2, *}, \dagger$

\begin{abstract}
Using tangible rewards is one of the most frequently used teaching strategies for teachers to manage the class, and it also has been one of the most controversial topics in both psychology and education research for decades. In China, the arising appreciation education philosophy and increasing attention to education draw people's attention to the use of tangible rewards in recent years. Also, the special Chinese teaching context has exacerbated the impact on the detrimental effects and potential benefits of tangible rewards on Chinese young students. In this article, we integrate theories as well as research findings and summarize the key disadvantages, advantages, and necessity of using tangible rewards with Chinese young students. Subsequently, we indicate key factors influencing the effectiveness of using tangible rewards and give suggestions for using tangible rewards strategy. These include the following: 1) don't overuse tangible rewards, 2) diversify the tangible rewards, 3) giving rewards not only to individuals also to groups, 4) make sure the fairness of giving rewards to each child.
\end{abstract}

Keywords: Tangible rewards, Intrinsic motivation, Chinese students, Education.

\section{INTRODUCTION}

According to the school of Behaviorism, classroom rewards are reinforcers for teachers to encourage students to maintain and increase desired behavioral performance in classroom teaching. Some scholars also believe that classroom reward is a series of external incentive strategies for students when teachers fail to complete their teaching tasks [1]. They can be divided into different forms, such as internal and external rewards or material and spiritual rewards [2]. External and material rewards mean something visible and impalpable such as candies, toys, and small gadgets, while internal or spiritual rewards generally refer to that invisible but perceivable stuff that is able to induce a sense of self-fulfilment, such as verbal praises [3]. Moreover, some researchers consider that tangible rewards are classified into anticipated rewards and unanticipated rewards according to the time they receive them [4]. Anticipated rewards mean the promised gift existing before participation in an activity, and unanticipated rewards refer to the gift they get during or after the activity.
At present, tangible rewards are one of the most common teaching strategies for teachers to manage the classroom with young students [5]. They have been regarded as a useful and normal tool in the teachinglearning process in many countries and they are regarded as the simplest, most direct, and most adaptable approaches for addressing the value aspect of motivation [6]. They refer to the kind of rewards that the teacher gives students to recognize and praise them for a work well done, and they are given as motivation and are contingent on desired outcomes being achieved [7]. In China, tangible rewards are more frequently used with students from kindergarten to primary school. Researchers found that the most commonly used tangible rewards in China are verbal rewards, behavior rewards, and token rewards [8]. In this case, verbal rewards refer to praise; behavior rewards refer to the form of facial expressions, gestures, and body movements to encourage students; token rewards refer to the material rewards, or tokens can be used to exchange other tips or privileges. In recent years, appreciation education philosophy, children abuse incidents, and students' mental health have been 
extensively concerned in China; the discussion of using tangible rewards is practically significant [9-10].

Nowadays, the efficacy and function of tangible rewards remain contentious in both psychology and pedagogy field, some scholars are not in favor of it. The first reason is the criticism of tangible rewards regarding the detrimental effect on students' intrinsic motivation [11-16], students are likely to only focus on what kind of tangible reward they can get rather than what experience they can lean during the completion process under the temptation of tangible reward. The second most common rebuttal is some researchers think tangible reward is unethical and is another form of bribery, which will indirectly teach young students bribing behaviours [17]. The third reason is that the process of reward evaluation criteria from teachers can be too subjective and unfair, and will conversely demoralize young students to reach their goals [18]. In addition, as Chinese learning context is typically examination-oriented, teachers formulate and decide all the materials and procedures in a big-sized class, educators and psychologists take particular concern about the disadvantages of using tangible rewards with Chinese students [19].

Whereas, the advantages and necessity of tangible rewards are obvious. Many psychologists and educators oppose the criticizers' beliefs; and argue that, instead, there is a positive and additive relationship between intrinsic motivation and tangible rewards [20-22]. Also, researchers found the pleasure received from tangible rewards can enhance children' $\mathrm{s}$ self-esteem, confidence, and self-efficacy [9,23]. Moreover, tangible rewards benefit young students in socialization development and building harmonious teacher-student relationships [24]. Not only do the above advantages support the use of tangible rewards, but many observers mention the necessity of using tangible rewards with young students. Tangible rewards are promoted by teachers in kindergarten and primary school because this type of reward system accords with young students' nature. For example, tangible rewards are unique tools for young students by meeting their fundamental psychological demand, enhancing their attention and being unaffected by their limited abstraction capacity [25-28].

However, different types or combinations of tangible rewards should be used in different conditions. Many Chinese educators focus on the efficiency of tangible rewards in teaching practice and observe the young students' learning outcomes by experimenting with different forms of tangible rewards, reward objects, reward timing, and reward orientation [29]. Many research examine the effectiveness of tangible rewards given different factors, such as students' personalities and gender.
Based on the above-mentioned literature, considerable theoretical and experimental results are given in this controversial topic, especially for Chinese young students. This review aims to summarize the disadvantages and advantages of using tangible rewards with Chinese young children. We critically discussed the scenarios of using tangible rewards more effectively and gave some suggestions of using tangible rewards with Chinese young students. Also, in this review, 'Chinese young children' is regarded as the student from kindergarten to primary school in China and 'tangible rewards' refers to the external rewards generally used in China such as material rewards and praise.

\section{MAIN BODY}

\subsection{Disadvantages}

\subsubsection{The relation between tangible rewards and student's intrinsic motivation}

Some scholars hold a negative attitude towards the use of tangible rewards. There're three main reasons why they're not in favor of it. The most common rebuttal against tangible rewards is its adverse effect imposed on students' intrinsic motivation. Specifically, the tangible reward is likely to shape students from intrinsically motivated to intrinsically motivated. Intrinsic motivation is defined as doing an activity for its inherent satisfactions rather than for some separable consequence. When intrinsically motivated, students are moved to act for the fun or challenge entailed rather than because of external products, pressures, or rewards [30]. While extrinsic motivation can be embodied as a kind of reward-driven behavior, extrinsically motivated students are usually propelled by external rewards such as toys or praises. While these scholars posit that the intervention of tangible reward is likely to result in a change in concentration as well as a slump in students' perceptions of competence and self-determination, thereby decreasing their intrinsic motivation to perform the task. In other words, students may shift their attention initially from what knowledge they're supposed to learn to what sort of tangible reward they are able to receive for a wonderful result. This shift of their mentality totally runs counter to the teacher's initial goal of teaching. Therefore, some researchers think teachers should replace tangible rewards with the kind of teaching focused on the student's intrinsic motivation. A common goal should be to have the student's interest be at the center of their learning, not a reward. Students who perceive themselves as causal agents in the classroom engage in more risk-taking behavior and improve their performances [31]. Also, students who perceive themselves as more in control of learning have better self-esteem [32]. 


\subsubsection{The correlation between tangible rewards and bribes}

The second concern that researchers mainly have is about the correlation existing between tangible rewards and bribes. They reckon that the process of dispensing tangible rewards is tantamount to giving bribes. Bribes can be defined as a so-called gift bestowed to another person to seduce him into doing something to achieve the presenter's goal, while some people think that the use of external rewards, even verbal praise, can be considered bribery to make students temporarily submissive and obedient to the teacher as well as being dependent on the teacher's approval [33]. This perspective is prevalent not only in teacher's education programs but in society as a whole. Therefore, doling out tangible rewards can be an indirect way to teach student's the behavior of bribing, and students are apt to use tangible rewards to control others. The research found that children aged 3-6 who were in a token program were observed hiring the services of one another, and it seems quite possible that the recipients of reinforcers will model the methods of the token giver. The recipient of the reinforcers may learn to control others by promises of gifts, material goods, and services [34].

\subsubsection{The nexus between tangible rewards and misuse}

The third rebuttal pertains to the current circumstance of tangible rewards' use. Nowadays, a majority of teachers are not aware of the correct use of tangible rewards, and the misuse is prone to trigger many inimical effects on their students' mental and academic development. And the damaging effects are mainly the result of two phenomena, the overjustification effect, and the unfair distribution.

\subsubsection{The overjustification effect}

The overjustification effect is a phenomenon in which being rewarded for doing something diminishes intrinsic motivation to perform that action. Researchers have found that when extrinsic rewards (such as money and prizes) are given for efforts that students already find intrinsically rewarding, they become less internally motivated to pursue those activities in the future, students tend to pay more attention to these external rewards rather than their own enjoyment of the activity. Since students feel like they are being "bribed" into performing the behavior, they assume they only do this external reinforcement. For example, imagine that children at a preschool can play with fun toys during their free time. If caregivers begin rewarding kids for playing with these toys, the children may start to feel less intrinsically motivated to play with those toys [35].
Therefore, too many rewards giving will lead to a paradoxical impact on student's performance.

\subsubsection{The unfair distribution}

Teachers' judging criteria in the process of reward evaluation can be too subjective and unfair. Sometimes, the standards are only suitable for a small portion of students rather than most of the class. During this process, teachers are likely to ignore other students' feelings. Furthermore, at present, the rewards are mostly too broad, practical, and superficial. The effect is not ideal, for the excessive use of classroom rewards can lead to the excessive dependence of primary school students, in the long run, it is harmful to students' motivation to study [36].

\subsection{Advantages}

\subsubsection{The critique of undermining effects on intrinsic motivation}

However, the above claims of the detrimental effect on intrinsic motivation have been strongly contested in decades by a number of writers. On the contrary, they believe intrinsic motivation is reinforced by tangible rewards. Eisenberger, Pierce, and Cameron have found tangible rewards based on performance increase individuals' self-determination and intrinsic motivation [20]. Likewise, based on Social-Cognitive Theory, Hidi have suggested tangible rewards can lead a student generate interest in specific activity then eventually contribute to more general involvement in a subject area, and to overall intrinsic motivation [37]. Unlike Eisenberger and his team's findings, the social-cognitive theory does not emphasize the enhancement in selfdetermination. Indeed, it indicates tangible rewards from achieving challenging performance lead to higher personal evaluations and increased competence. Similarly, Covington and Müeller have found tangible rewards frequently bolster personal engagement in learning [20]. In this regard, scholarship is an appropriate example, leading students to work hard and improve their academic level. Based on several studies and practical experience, they also have found that tangible rewards can support intrinsically oriented endeavors, as well as sustain personal interest even after one's initial curiosity has faded. This effect tends to be especially concerned on young students because they are easier to be affected by external stimuli and their curiosity is more likely to fade. This may explain why tangible rewards are frequently used by kindergarten teachers. Moreover, neuroscientists have repeatedly pointed to the importance of rewards and admitted rewards play essential roles in goal-directed behavior and learning in recent years. For example, some neuroscientific research have found that rewards and reward cues can enhance cognitive behavior and have 
longer-lasting and more pervasive effects, which in turn increase intrinsic motivation [22]. Overall, there is a positive and additive relationship between intrinsic motivation and tangible rewards.

\subsubsection{The enhancement on children's self- esteem, confidence, and self-efficacy}

The pleasure received from tangible rewards is beneficial for young students' self-development. Considerable studies imply tangible rewards are effective tools to boost young students' confidence [23]. Especially in recent years, China have shown a growing trend of humanistic education. Some people advocate "success education" and "appreciation education" with the use of tangible rewards as a dominant mode in school and family education because of the rising awareness of enhancing confidence and self-esteem. Also, to be precise to class effectiveness, a study found tangible rewards make young students more active to participate, open to express opinions, and not afraid to make mistakes in the class [38]. In addition, studies find that the pleasure generated from tangible rewards can develop students' self-efficacy, and contribute to a positive influence in children's academic ability and health level [9].

\subsubsection{The Benefits in children's socialization development}

Sociologists and Symbolic Interaction Theory suggest that using tangible reward is a process of social interaction between teachers and students based on certain symbolic signs and it is one of the most important ways for young students to gain self-concept and complete socialization development [24]. From this view, tangible rewards are a useful tool to help children to cultivate good behavior and character, form optimistic views about self and consciousness, and enhance the role-taking capacity in society. Also, through such social interaction, young students can build positive teacher-student relationships in the school. These values are important for any human, especially for young students in the zone of proximal development.

\subsubsection{The necessity of using tangible rewards with young students}

For many educators in China, the necessity of using tangible rewards with young children is highlighted. They seen tangible rewards are one of the most appropriate tools for teaching children. Inlined with the above-mentioned socialization development theory, receiving tangible rewards is the fundamental psychological demand for children [27]. Young students need this kind of positive social or symbolic interaction with teachers of their age, especially Chinese teachers who play a dominant social in the teaching-learning context at school. Furthermore, Kotaman have found children preferred the tangible reward over others because of children's limited abstraction capacity, which means tangible rewards are more effective and easier to understand for young children who cannot evaluate the future value of their behavior [25]. Therefore, tangible rewards are essential tools for teachers to use in kindergarten and primary school.

\subsection{Factors influencing the use of tangible rewards}

However, practical context is more complicated, and tangible rewards' effectiveness can be different in diverse conditions. In China, tangible rewards are divided into mainly three types: 1) verbal rewards, 2) behavior rewards, and 3) token rewards. Many educators found the most frequently used types of tangible rewards in China are verbal rewards because they are the simplest and most feasible way for teachers with no restriction by conditions such as time and location [26]. Considerable psychologists and educators agree with the advantages of verbal rewards. From Cameron and Piere' s view, verbal rewards will increase intrinsic motivation while other tangible rewards may influence intrinsic motivation in different conditions [21]. Verbal rewards, usually have obvious information characteristics, deliver more positive effects on students' intrinsic motivation and competence than the material forms [15]. It also means, teachers should explain to young students why they give rewards in the verbal praise so that children can distinguish the right behaviour to develop. However, if teachers overemphasize the students' earnestness and hard work in the verbal praise, the praise at this time has obvious controlling characteristics, leading to detrimental effects on intrinsic motivation [29]. But some other researchers remain different views of verbal rewards. Tingyu Li have found material rewards can promote children's empathy and altruistic helping behavior tendency but verbal rewards will reduce this tendency [39].

Age is a significant factor when teachers consider using tangible rewards strategies. For example, in kindergarten, verbal rewards are more frequently used with the senior grade since students are more concerned with emotional needs and are less attracted by the material rewards such as stickers and candies [28]. However, the educational value tends to diminish as the abuse of verbal rewards by Chinese teachers in recent years. Also, tangible rewards are given to a group of students instead of individuals when they move from kindergarten to primary school. Thus this strategy may help children to develop the team working skills. But some criticism of this group reward strategy claims that using this strategy is teachers fail to pay attention to 
each student because of the big-sized Chinese class, which is contrary to the original intention of giving rewards [28].

Timing is also essential for rewards strategy. Tangible rewards can be more effective on young students when they receive them in time, which means rewards should be given to children immediately when they perform an encouraging behavior. This is because, for children with immature physical and mental development, offering rewards in time can help children clearly realize the connection between their behavior and the rewards from the behavior [26]. Sun' s studies have discovered that the time interval and frequency of using rewards should be flexible during learning the right behavior. The frequency should decrease, and the time interval should be longer when children being more familiar with the new skill or behavior.

Moreover, it is more effective to reward the young students in public because it will positively influence students and set a good example to other students. In the long run, this strategy will cultivate students' collective consciousness and help children enhance social skills.

In conclusion, the types of tangible rewards, the age of applied students, the timing and occasion of giving rewards are importantly influenced the effectiveness of using tangible rewards by Chinese teachers.

\subsection{Suggestions}

Reward are imperative methods in children's education. We need to be clear that the goal of rewarding is not for the completion of rewarding, but the release of students' intrinsic motivation and potential. We need to try our best to evade the deficits and misunderstandings of tangible rewards and use our external rewards correctly to unleash every children's latent capacities and promote their development in an all-around way. Here are four suggestions for using tangible rewards.

\subsubsection{Don't overuse tangible rewards}

Due to the student's limited understanding, it is less effective to stimulate their intrinsic motivation to study by talking about the significance of study, which is too abstract and lengthy for them to understand. In this case, Tangible rewards are a great way to inspire those students whose motivations and desires to study are in deficiency. However, when the students are gradually motivated, it's necessary for teachers to lessen the extent of tangible rewards. Otherwise, it will extrinsically impact the student's study motivation and finally transfer the student's concentration from study to tangible rewards [40]. Therefore, teachers should control the number of tangible rewards as well as the opportune time to present them to students.

\subsubsection{Don't reward the students only in one form}

At present, a significant number of parents in China are prone to reward their students in only one form, which is the tangible reward [40]. However, the research revealed that teachers could use tangible rewards effectively to enhance or maintain an individual's intrinsic interest in activities when the rewards appear in alignment with verbal praises [41] Therefore, teachers should diversify their rewarding forms to let the rewards come into effect to the greatest extent.

\subsubsection{Don't set individual tasks all the time}

Students should make progress through cooperation rather than individual competition. However, nowadays, in China, most tangible rewards are presented under tasks that teachers have set for students to complete independently [42]. This phenomenon is likely to be an impediment to their sense of collaboration. Students will lack the ploys of setting partnerships with others, which will do great harm to their comprehensive competency. Therefore, the teacher can divide the whole classmates into different groups, assign some tasks required for group-working, and then reward the most outstanding group.

\subsubsection{Don't set unfair rules}

When teachers are making rules for the rewarding system, they need to focus on the impartiality of the practice. They should consider every student's characteristics and make a reasonable rule entirely accepted by the majority of the students. Suppose the students are under an unfair rule for a long time. In that case, it is very likely for them to develop learned helplessness, which means a state that occurs after a person has experienced a stressful situation repeatedly. They come to believe that they are unable to control or change the situation, so they do not try - even when opportunities for change become available [43]. In the long run, the intrinsic motivation of students will be undermined severely. Therefore, teachers should make the rule of giving tangible rewards as reasonable as they can.

\section{CONCLUSION}

Our paper concludes the advantages and disadvantages of tangible rewards used on Chinese young students. Most educators in Chinese agree with the use of tangible rewards with young students but emphasize the correct strategy of using tangible rewards. By considering the Chinese teaching context, we identify the effectiveness of using the tangible rewards usually influenced by the types of tangible rewards, the age of students, the timing and occasion of 
giving rewards. This study also has identified some suggestions for schools and teachers, 1) don't overuse tangible rewards, 2) diversify the tangible rewards, 3) giving rewards not only to individuals also to groups, 4) make sure the fairness of giving rewards to each child.

Still, we only analyze the current circumstance of real rewards in Chinese elementary schools, and Chinese culture is a quintessence of collectivism. The other western countries' culture embodies individualism, and the conclusion may not be able to apply to other elementary school students with a different cultural background. For example, the most frequent conduct issues and classroom removals and suspensions were reported by American pupils. Students in China said the most pleasant teacher-student interactions and the most frequent usage of prizes and praise by their teacher [44]. Therefore, Cultural values likely contribute to some differences in students' performances. So from my perspective, researchers in the future can put their research's emphasis on the cultural background of the sample students and compare the students' performances under different cultural backgrounds.

\section{REFERENCES}

[1] J. Chen, Disscussion on the Application of Reward Mechanism in Primary School Teaching, 2018

[2] M. Gu, M. Zhou, The Reward Strategy of J Call Teacher under the Theory of Cognitive Evaluation, 2021

[3] Christopher Knapper, John R. Kirby Patrick Lamon \& William J. Egnatoff (2010) Development of a scale to sure lifelong learning, International Journal of Lifelong Education, 29:3, 291-302, DOI: $10.1080 / 02601371003700584$

[4] Ryan, R. M., Mims, V., \& Koestner, R. (1983). Relation of reward contingency and interpersonal context to intrinsic motivation: A review and test using cognitive evaluation theory. Journal of Personality and Social Psychology, 45(4), 736750. https://doi.org/10.1037/0022-3514.45.4.736

[5] Kotaman (2017) Impact of storybook type on kindergarteners' storybook comprehension, Early Child Development and Care, 187:11, 1771-1781, DOI: $10.1080 / 03004430.2016 .1188297$

[6] Brophy, J. (2004). Motivating Students to Learn (2nd ed.). Routledge. https://doi.org/10.4324/9781410610218

[7] J. Am. Chem. Soc. 1970, 92, 24, 7149-7153 Publication Date: December 1, 1970 https://doi.org/10.1021/ja00727a021

[8] Y. Wu, Comparison of material rewards and praise, 2014
[9] C. Zhou, Research on the Status Quo of Teachers' Reward Application in the Collective Teaching Activities of Middle Class[D], Liaoning Normal University, 2016

[10] Z. Yang, Study on rewards and punishments of preschool teachers - - Based on teacher A's teaching narrative, Shanxi university, 2020

[11] J. Sun, Bensalem, M. Bogza, A. Legay, T.H. Nguyen, J. Sifakis, R. Yan, Incremental component-based construction and verification using invariants, in: Proceedings of the Conference on Formal Methods in Computer Aided Design (FMCAD), IEEE Press, Piscataway, NJ, 2010, pp. 257-256.

[12] Vansteenkiste, M., Niemiec, C. P., \& Soenens, B. (2010). The development of the five mini-theories of self-determination theory: an historical overview, emerging trends, and future directions. Emerald.

[13] Kohn, A. (1999). Punished by Rewards: The Trouble with Gold Stars. In Incentive Plans, A's, Praise, and Other Bribes.

[14] Lavorata, B. (2013). Undermining Intrinsic Motivation. SFU Educational Review, 6. https://doi.org/10.21810/sfuer.v6i.371

[15] Deci, E. L., Koestner, R., \& Ryan, R. M. (2001). Extrinsic Rewards and Intrinsic Motivation in Education: Reconsidered Once Again. Review of Educational Research, 71(1), 1-27. https://doi.org/10.3102/00346543071001001

[16] Lepper, M. R., Greene, D., \& Nisbett, R. E. (1973). Undermining children's intrinsic interest with extrinsic reward: A test of the "overjustification" hypothesis. Journal of Personality and Social Psychology, 28(1), 129-137. https://doi.org/10.1037/h0035519

[17] C. Qiu, Comparison of material rewards and praise and its enlightenment to primary education, 2021

[18] X. Zhang, Takes pork, rice and moon cakes to some rural primary schools in western Guangdong as an example, 2018

[19] L. Qin, The Application of Achievement Motivation Theory in Teaching Practice under the Background of Chinese Education, Charming China, 2017

[20] Covington, M. V., \& Müeller, K. J. (2001). Intrinsic Versus Extrinsic Motivation: An Approach/Avoidance Reformulation. Educational Psychology Review, 13(2), 157-176. https://doi.org/10.1023/A:1009009219144 
[21] Cameron, J., Pierce, W. D., Banko, K. M., \& Gear, A. (2005). Achievement-Based Rewards and Intrinsic Motivation. Journal of Educational Psychology, 97(4), 641-655. https://doi.org/10.1037/0022-0663.97.4.641

[22] Hidi, S. (2016). Revisiting the Role of Rewards in Motivation and Learning: Implications of Neuroscientific Research. Educational Psychology Review, 28(1), 61-93. https://doi.org/10.1007/s10648-015-9307-5

[23] H. Liu, Analysis of Strategies and Effects of Implementing Reward for Preschool Teachers, Journal of Chengdu Normal University, 2018

[24] Y. Yu, The Missing Representation and Reconstruction Path of Reward in Education from the Perspective of Social Interaction Theory, Contemporary Educational Science, 2019

[25] Kotaman, H. (2019). Children's choice: motivation after successful completion of a mathematics task. Early Child Development and Care, 189(5), 811819. https://doi.org/10.1080/03004430.2017.1344978

[26] J. Sun, Research on Kindergarten Teachers' Reward Strategies for Children, Northwest Normal University, 2008

[27] L. Fang, Analysis on the Mechanism of Rewarding Educational Function in Preschool Moral Education, SOCIAL SCIENCES REVIEW, 2005

[28] D. Qi, A Study on Teachers Reward Behavior in Kindergarten Collective Education Activities, Central China Normal University, 2017

[29] S. Yuan, A Study on the Intrinsic Motivation Effect of External Reward in Primary School English Learning, Basic Foreign Language Education, 2015

[30] Richard M. Ryan, Edward L. Deci, Intrinsic and Extrinsic Motivations: Classic Definitions and New Directions, Contemporary Educational Psychology, Volume 25, Issue 1, 2000, Pages 54-67, ISSN 0361-476X,

https://doi.org/10.1006/ceps.1999.1020.

[31] RICHARD DECHARMS, First published: June 1972 https://doi.org/10.1111/j.15591816.1972.tb01266.x

[32] Ryan, R. M., \& Grolnick, W. S. (1986). Origins and pawns in the classroom: Self-report and projective assessments of individual differences in children's perceptions. Journal of Personality and Social Psychology, 50(3), 550-558. https://doi.org/10.1037/0022-3514.50.3.550
[33] Kohn, Choices for Children Why and How to Let Students Decide http://www.alfiekohn.org/article/choiceschildren/?print=print, 1993

[34] Don Bushell Jr., Patricia Ann Wrobel, Mary Louise Michaelis, First published: Spring 1968 https://doi.org/10.1901/jaba.1968.1-55

[35] Kendra M. Cherry Eric J. Lenze, and Catherine E. Lang $15 \quad$ JUN 2014 https://doi.org/10.1152/jn.00882.2013

[36] J. Sun, Negative effects and coping strategies of primary education reward, 2020

[37] Hidi, S., \& Harackiewicz, J. M. (2000). Motivating the academically unmotivated: A critical issue for the $21^{\text {st }}$ century. Review of Educational Research, $70,151-179$.

[38] Cahya, T., Kusnadi, A. N., \& Anggraeni, A. (2018). The Influence of Tangible Rewards To Student'S Motivation in 4Th Grade Sdn Sinargalih 1 Ciranjang Students. PROJECT (Professional Journal of English Education), 1(4), 350-356.

[39] T. Li, X. Gai, The influence of rewards on children's empathy and altruistic helping behavior tendency, 2012

[40] Z. Yu, On the importance of Students' Learning Motivation, 2002

[41] Cameron, Judy, and W. David Pierce. "Reinforcement, Reward, and Intrinsic Motivation: A Meta-Analysis." Review of Educational Research 64, no. 3 (September 1994): $363-$ 423. https://doi.org/10.3102/00346543064003363.

[42] X. Hou, Teaching incentive policy design looks at it from the motivation "crowding effect", 2020

[43] Carlson, Neil $\quad$ R. 2010 https://lib.hpu.edu.vn/handle/123456789/28533

[44] Bear G G , Chen D , Mantz L S , et al. Differences in classroom removals and use of praise and rewards in American, Chinese, and Japanese schools[J]. Teaching and Teacher Education, 2016, 53:41-50. 